\title{
ACCIDENT CHARACTERISTICS OF ROHTAK-KHARKHODA SECTION OF SH-18
}

\author{
Naveen Rathee ${ }^{1}$, Shashank Sharma ${ }^{2}$ \\ ${ }^{1,2}$ Department of Civil Engineering, Deenbandhu Chhotu Ram University of Science and Technology, Murthal, \\ Sonipat (Haryana)
}

\begin{abstract}
The increase in road accidents is one of the biggest issues in the present society. This problem relies heavily on the use of private vehicles, especially VRUs, which have created social problems due to loss of lives, and this is due to complete failure of transport system. In the field of accident analysis and formulation of accident strategies, accident data becomes a starting point. The main objective of the study is to find accident prone area on the Rohtak - Kharkhoda section of SH-18 from First Information Report and to study the traffic conditions on this road stretch andto identify safety measures and provide recommendations for solving deficiencies on this road. The road selected for the study is $30.6 \mathrm{~km}$ stretch of SH-18 in Haryana from Shiela Bypass to Kharkhoda. From the data analysis, it can be analyzed that more number of accidents have occurred in the year 2013 and mostly occurred during 8a.m to 10a.m and 4p.m to 6p.m.From analysis, it is found that the trucks and two wheelers contribute more accidents. It was observed that road width, fade markings, broken shoulder, high traffic (PCUs), high speed, heavy cross movement of pedestrian, unauthorized median opening, absence of curve indicators on curve, trees by road side, erosion of shoulders due to cart tracks and footpaths or cattle crossing, places of worships, wayside bus stop without bus bays and poor road conditions causing accidents. From the result analysis, it can shows that road needs upgradation. Provide sufficient roadway width, change the alignment of road on horizontal curves to enhance adequate sight distance, remove illegal constructions from the road, provide necessary traffic rules and pedestrian crossing and median opening were redesigned to provide better facility for VRUs and road users.
\end{abstract}

Keywords: Safety Analysis, Vulnerable Road Users, Accident Analysis, Black Spots, Road Safety.

\section{INTRODUCTION}

An unfortunate incident that happen unexpectedly and unintentionally typically resulting in damage or injury is termed as Accident. It has been observed that 13 people are dying per hour all over the world. The global status reports on road safety 2013 by WHO analyzed that the young people are the main victims of road traffic injuries due to mixed traffic flow on Indian highways. The "Accidental Deaths and Suicides in India, 2013" publication of NCRB shows that $1,37,423$ road accidental deaths were reported in the country during 2013. According to the Bloomberg Philanthropies Global Road Safety Programme (2010-2014), Indian government to implement some road safety programme and promoting safety for VRUs. Diageo (maker of Smirnoff vodka \& Johnnie Walker whiskey) also started road safety awareness programme with Institute of Road Traffic Education. The MORTH and the IRF will be the partners in the project (Sept 2014). Haryana is among one of the states with highest accidents. About $60 \%$ of the road accidents in Haryana occur on highways.

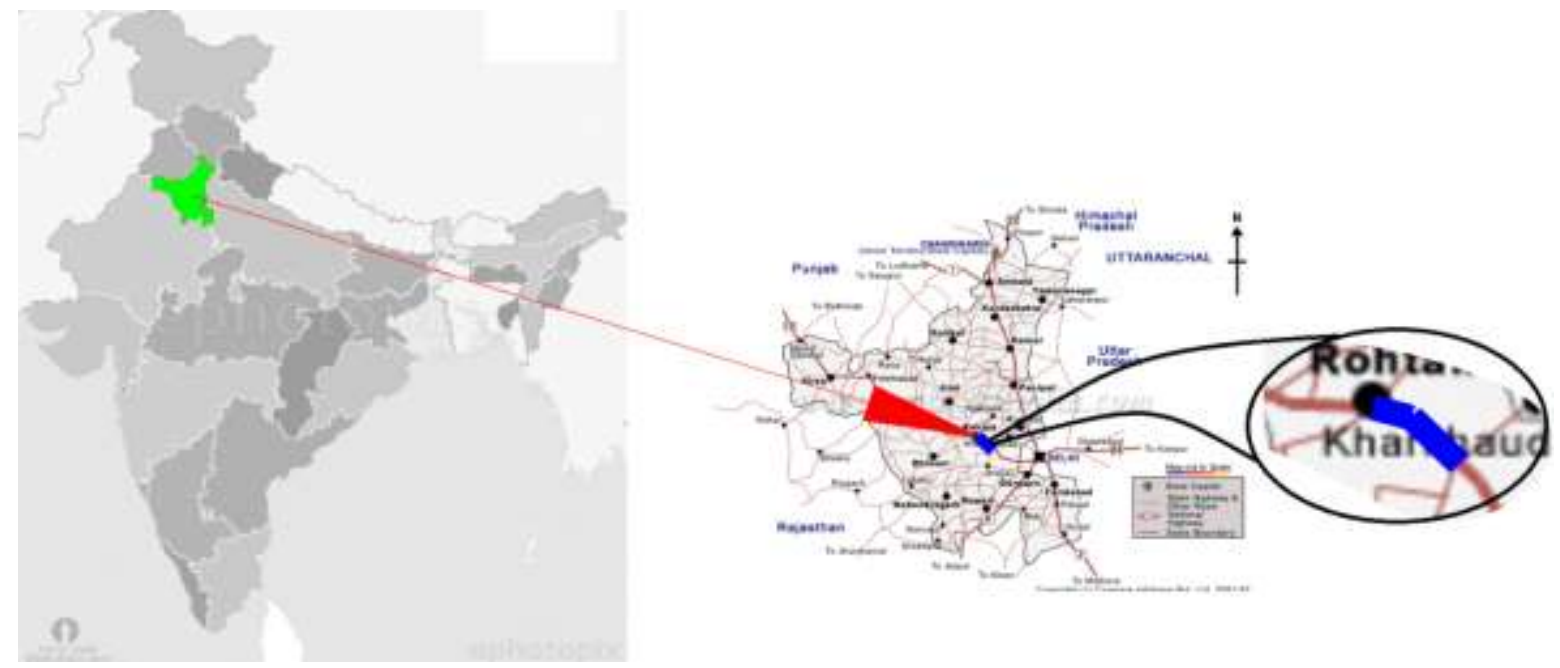

Figure 1: Showing the study area 


\section{Study Area}

In this paper stretch from $0.00 \mathrm{Km}$ to $30.6 \mathrm{Km}$ of State Highway 18 had been selected for analysis. This road is passing through HUDA Sector -4 , Sector -3 Sector -2 and number of villages like Bohar, Bhalot, Asan, Kansala, Hamayupur, Sisana. The section passing through villages are not left with enough space to accommodate the up coming traffic volume. The right of way is also narrow in such places. The selected highway stretch has been constructed with some portion of bituminous pavement and some portion of concrete pavement. The concrete pavement is in between Bhalot village (10.20 to $16.80 \mathrm{Km}$ ) and near byKharkhoda bus stand ( 28.4 to $30.6 \mathrm{Km}$ ) with carriageway width of 6.8 to $7.1 \mathrm{~m}$ having earthen shoulder of $1.4 \mathrm{~m}$ and rest of the selected road is of Bituminous pavement. The ROW is $20 \mathrm{~m}$ wide and it is designed for a speed of 80 $\mathrm{Kmph}$. However, in places where it has not been become possible to provide $20 \mathrm{~m}$ ROW due to social issues the alignment has been kept as it is with some minor improvement. The road passes through plain terrain. The condition of the carriageway is generally good.This State highway is maintained by Haryana PWD B\&R Department.

\section{Objectives}

The major objectives consists of following -

- Find accident prone area on theRohtak - Kharkhoda section of SH-18 from First Information Report.

- To study the traffic conditions on this road stretch.

- To identify safety measures and provide recommendations for solving deficiencies on this road.

\section{Salient features of study segment}

The road passes through plain terrain. The condition of the carriageway is generally good. Formation width varies from 8.3 to $11.8 \mathrm{~m}$ with carriageway varying from 5.5 to $7.0 \mathrm{~m}$. the right of way (ROW) is $20 \mathrm{~m}$. The crust consists of 2 to 3 bituminous layers followed by WBM with total thickness varying from $120 \mathrm{~mm}$ to $320 \mathrm{~mm}$. The subgrade is generally of good quality. In most of the section, the pavement is laid on the native soil where the embankment height is nil. The native soil consists of SILT/ Silty CLAY of low plasticity and Silty SAND. Some of the portions of road, rigid pavement has been laid comprising $15 \mathrm{~cm}$ DLC, $30 \mathrm{~cm}$ PQC and $15 \mathrm{~cm}$ of GSB.

\section{Review of Literature}

Literature includes the road safety concept, its origin, and expansion. One article describes the accident prone areas, geometrics and traffic conditions on the road stretch and give some relationship between factor causing and accident rates.. ${ }^{[1]}$ Anotheranalyzed the traffic safety and identify the reasons for crashes and give some important suggestion for road safety with linear regression model. ${ }^{[2]}$ One article summarized about the simulation technique and Mathematical modeling as well as Artificial Neural Network Technique to analyze the accident data and to develop models and computer programs and to predict future trend of probable occurrence of accidents using these scientific approaches and implement remedial measures in the field of traffic safety. ${ }^{[4]}$ Other article analyzed the accidents and shows that the main reason for accident are vehicle drivers because of poor condition of road. ${ }^{[3]}$ Yet another analyzed the accidents on two roads in plain \& rolling terrain and developed Two Highway Accident Rate Prediction Models $\left(\right.$ HARPM $\left._{\mathrm{PRT}} \& \mathrm{HARPM}_{\mathrm{MST}}\right)$ and shows that the model can be used for finding risk factors of the road and great support to the decision making of incident management in Intelligent Transportation Systems. ${ }^{[5]}$

With all the literature existing related to accident analysis, poor public transport system, roadway geometrics and traffic conditions and adopted some models and relationships to make them safe and to predict future trend of probable occurrence of accidents using these scientific approaches and implement remedial measures in the field of traffic safety.

\section{METHODOLOGY}

Three type of data was collected for this study on the identified section:

- Traffic volume count

- Accident data collection

- Spot Speed study

The above data was analyzed with the following objectives:

- Determine the main causes of accidents.

- Shortcomings in the geometric features of road.

- Accident due to vehicular movement.

- Effect of speed.

- Accident due to mixed traffic flow.

\section{ANALYSIS OF DATA}

\section{Traffic Volume Study}

Traffic volume count is used to assess (AADT) and traffic composition in PCUs. According to vehicle survey count, AADT was found 33276 PCUs. But, the capacity of vehicles on this road is 30,000 PCUs (Source: TCP, Haryana report 2014) which is less than the projected AADT, therefore volume to the capacity ratio is 1.10 i.e LOS on this road is " $F$ '. So, the increasing of traffic is the main cause of accidents due to more congestion and mixed traffic flow on this road. 
Table 1. Details of Traffic Volume in terms of AADT and PCUs as per Fast \& Slow driven vehicles.

\begin{tabular}{|c|c|c|c|c|c|c|c|c|c|}
\hline $\begin{array}{c}\text { Total } \\
\text { Survey }\end{array}$ & \multicolumn{6}{|c|}{ Fast Driven Vehicles } & \multicolumn{3}{|c|}{ Slow Vehicles } \\
\hline & Truck & $\begin{array}{l}\text { Tractor } \\
\text { Trailer }\end{array}$ & Bus & $\begin{array}{l}\text { Car/Jeep/ } \\
\text { Van/ Taxi }\end{array}$ & $\begin{array}{c}\text { Two } \\
\text { Wheeler } \\
\text { (Motorcycl/ } \\
\text { Scooter) } \\
\end{array}$ & $\begin{array}{c}\text { Total } \\
\text { Fast } \\
\text { Moving } \\
\text { Vehicles } \\
\end{array}$ & Cycle & $\begin{array}{c}\text { Animaldrawn } \\
\text { vehicles(ADV) }\end{array}$ & $\begin{array}{c}\text { Total } \\
\text { Slow } \\
\text { Moving } \\
\text { Vehicles } \\
\end{array}$ \\
\hline $\begin{array}{l}\text { Equivalency } \\
\text { Factor }\end{array}$ & 3.0 & 4.5 & 3.0 & 1.0 & 0.5 & & 0.5 & 4.0 & \\
\hline \multicolumn{10}{|l|}{ ADT } \\
\hline Numbers & 2726 & 964 & 640 & 11500 & 9700 & 25530 & 2626 & 295 & 2921 \\
\hline PCUs & 8178 & 4335.75 & 1920 & 11500 & 4850 & 30784 & 1313 & 1180 & 2493 \\
\hline Total PCU & r day & \multicolumn{8}{|c|}{33276} \\
\hline
\end{tabular}
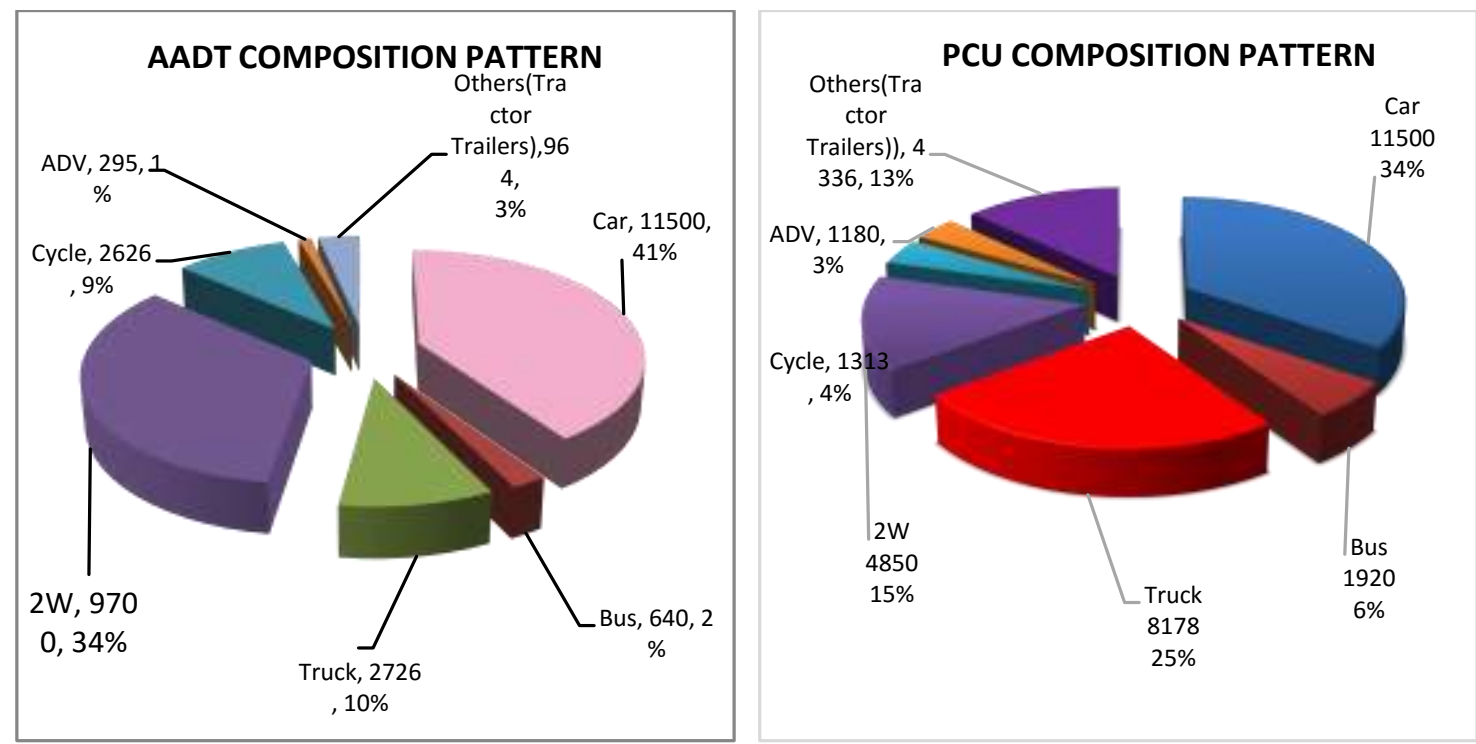

Figure 2: Traffic Composition of Vehicles in terms of AADT \& PCUs pattern

\section{Spot Speed data}

The spot speed survey was carried out on the state highway on Saturday at 9:30 AM to 10:15 AM by using stopwatch at $10.20 \mathrm{Km}$ near Bhalot village with a stretch distance of $100 \mathrm{~m}$. The survey continued until a sample size of 50 vehicles was measured. Details of percentile of speeds are as follows:

- The operating speedis higher than the design speed (80 Kmph).

- $85^{\text {th }}$ percentile speed of vehicles is $83 \mathrm{Kmph}$.

- $50^{\text {th }}$ percentile speed of vehicles is $63 \mathrm{Kmph}$.

- $15^{\text {th }}$ percentile speed of vehicles is $33 \mathrm{Kmph}$.

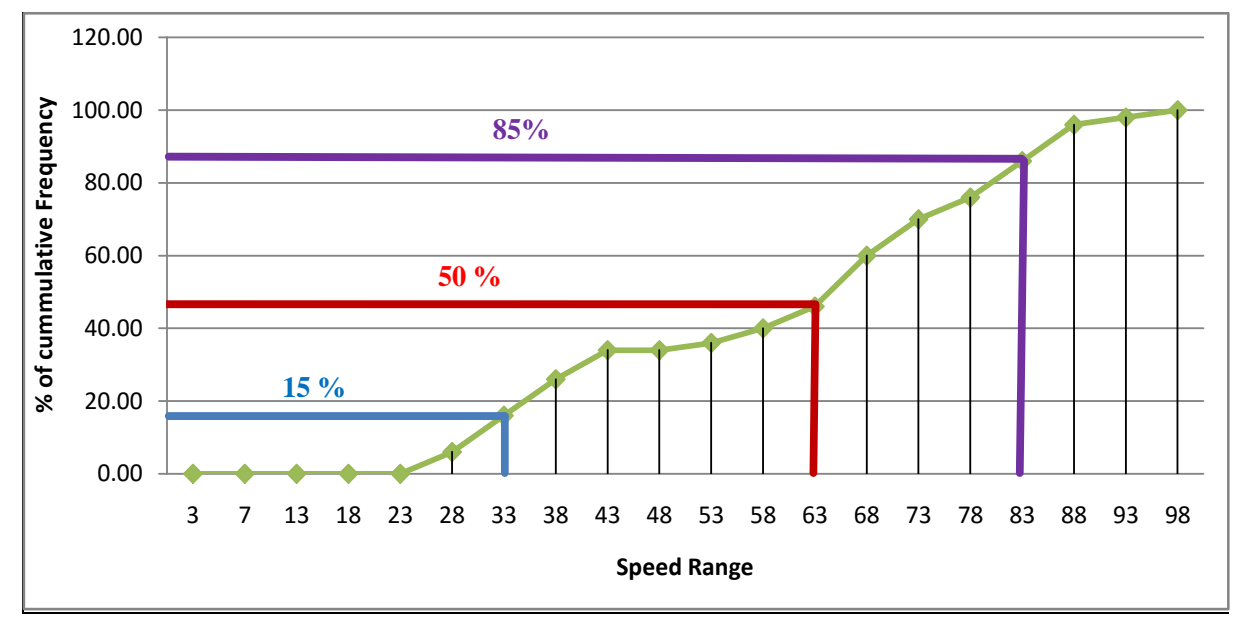

Figure 3: Cumulative frequency distribution curve of spot speeds 


\section{Accident Analysis}

It can be analyzed that the accidents are occurring on $\mathrm{SH}-$ 18 from 2011 - 2013, seems no significant change in accidents on this road.

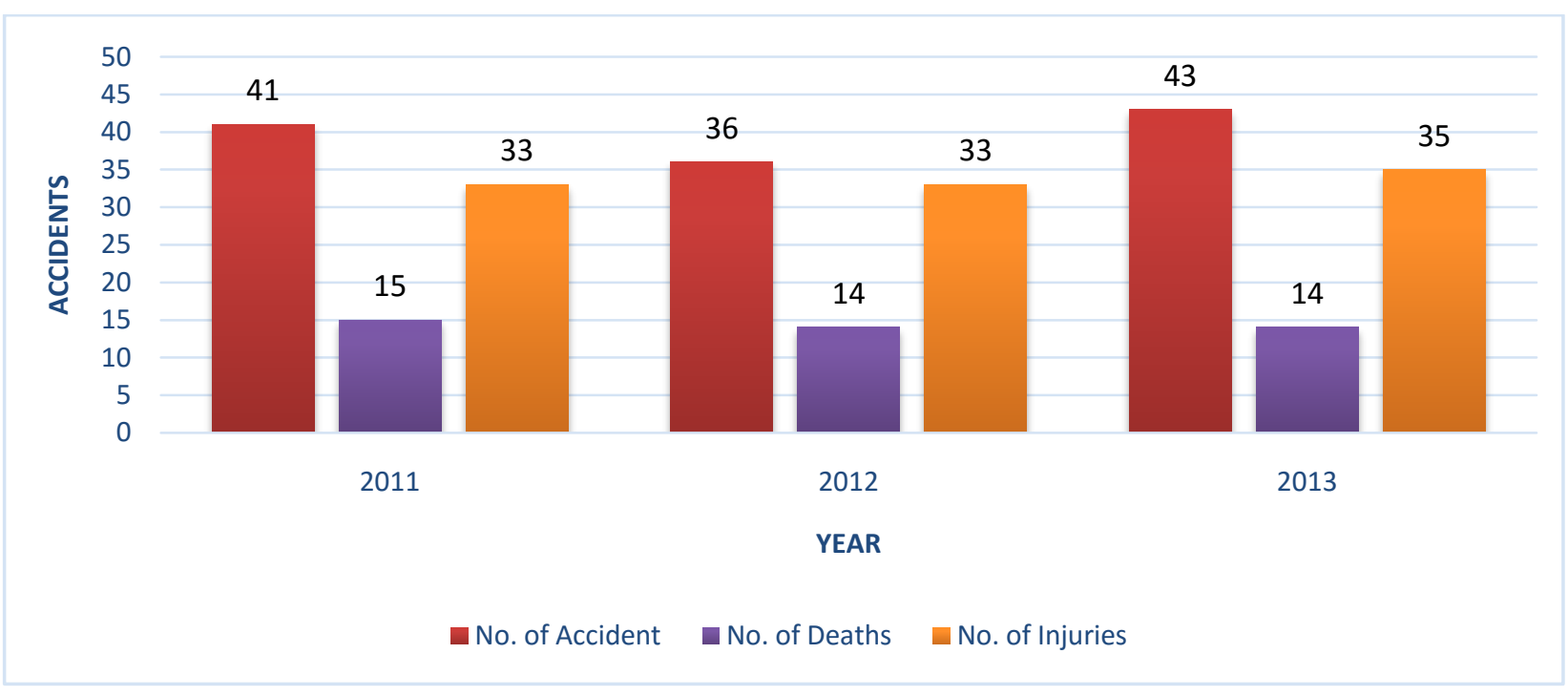

Figure 4: Accident details of SH-18

\section{Day wise Analysis of accidents}

It can be analyzed that the accidents are occurring on Friday, Saturday and Sunday.

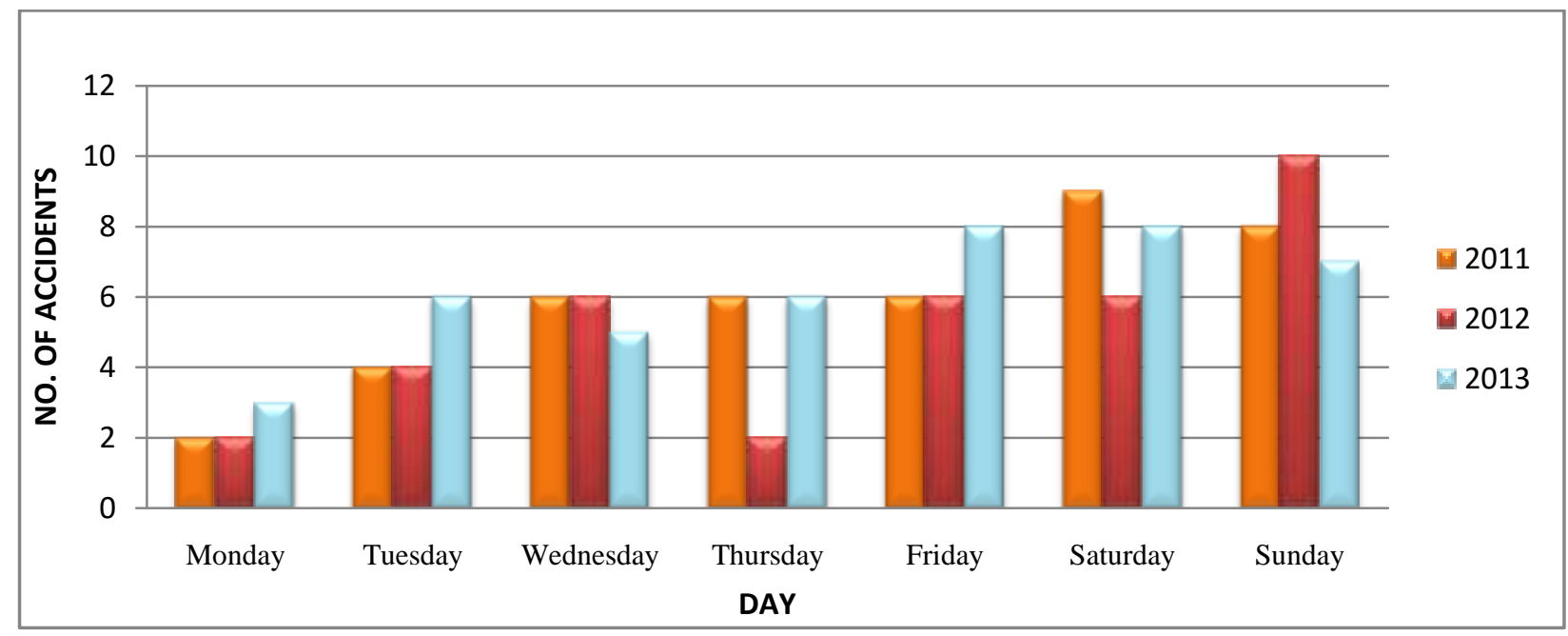

Figure 5: Day wise analysis of accidents

\section{Time wise Analysis of Accidents}

It can be analyzed that the accidents are occurring from 8:00 AM to 22:00 PM with a peak time of 18:00 PM 20:00 PM. The main reason of accidents in this interval is that most of the traffic running on road travels during this duration, poor lighting on this road is the main cause of peak time accidents and unauthorized median opening. In case of night accidents, the accidents are much less as compared to day accidents because of less traffic during late night hours. 


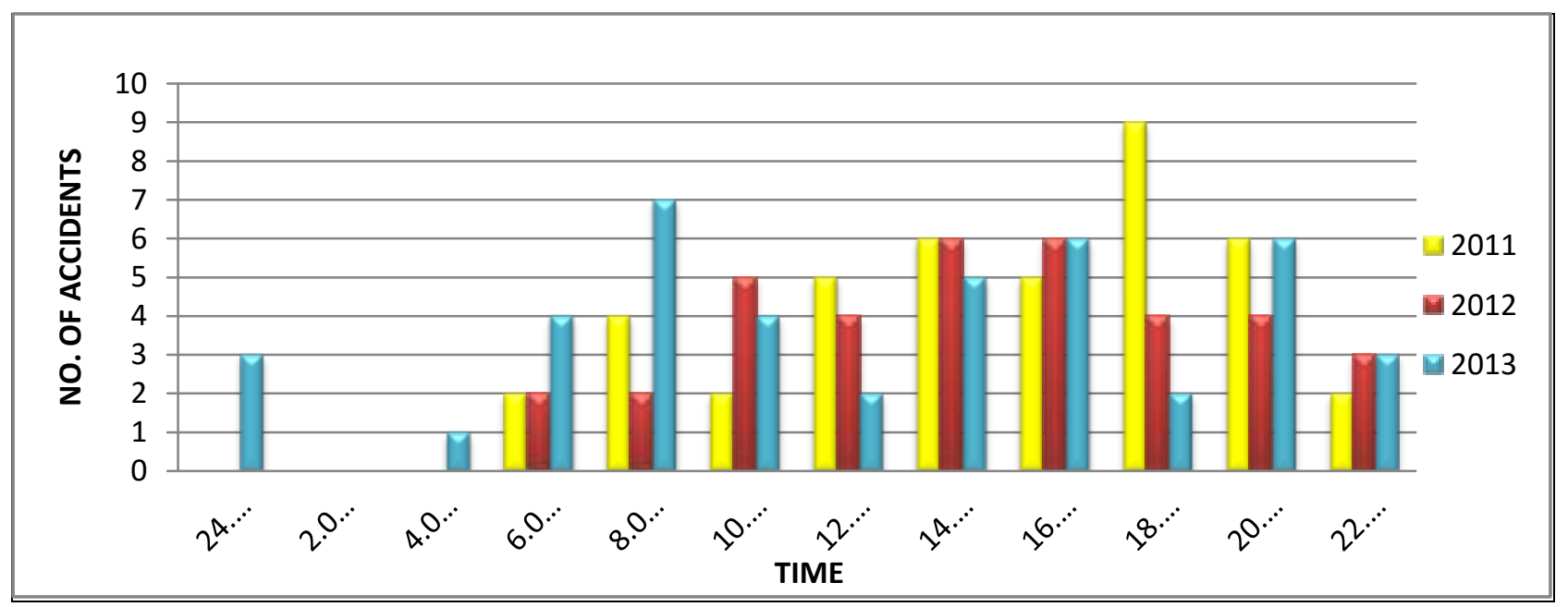

Figure 6: Time wise analysis of accidents

\section{Analysis of accident as per Hitting Vehicle}

It can be observed that motorcycles, car and trucks are the most dangerous vehicle on this road which tends to more accidents with their share of $31.71 \%, 26.83 \%$ and $19.51 \%$ in $2011,25 \%, 33.33 \%$ and $25.00 \%$ in
$2012,20.93 \%, 25.58 \%$ and $23.26 \%$ in 2013 . The main reason of accidents as per hitting vehicle is the high \% of involvement of these three category of vehicles may be due to their higher share in traffic and higher speeds.

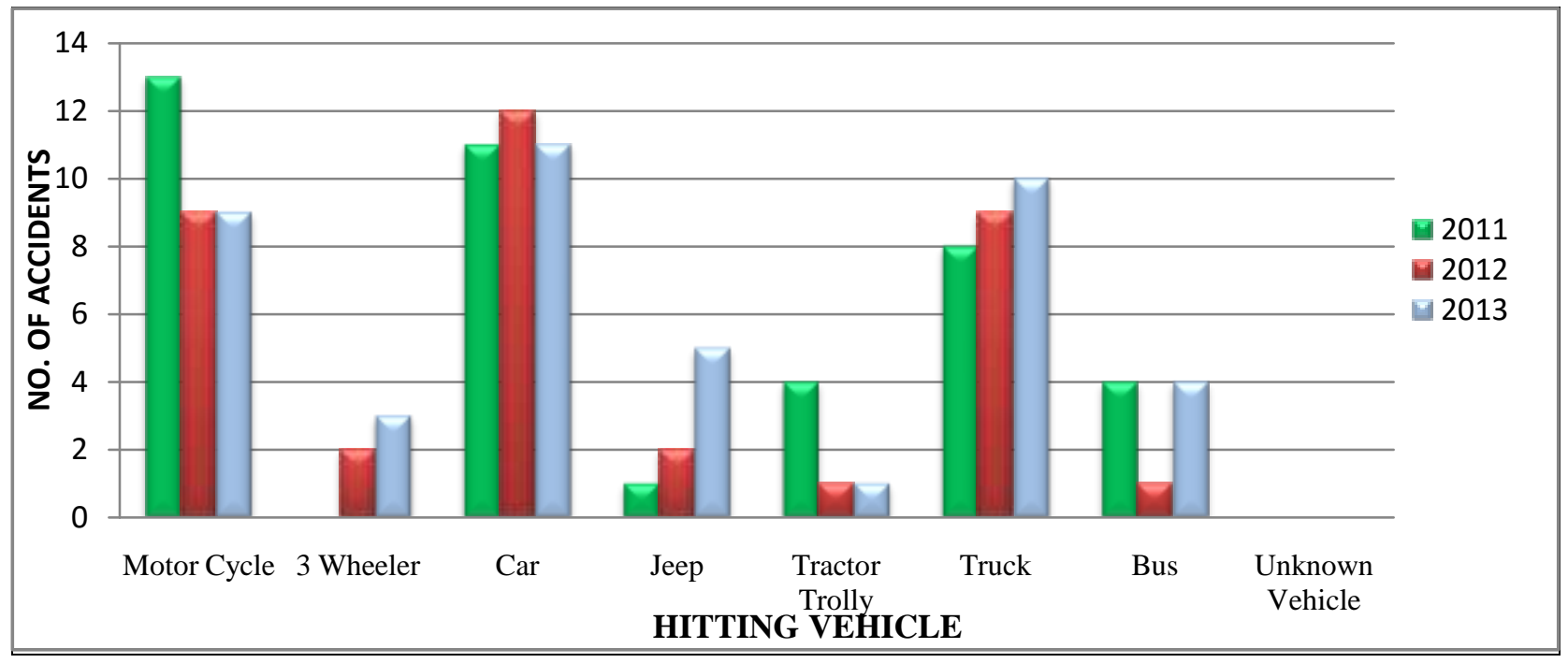

Figure 7: Analysis of accidents as per hitting vehicle

\section{Analysis of accident as per Vehicle Hit}

It can be observed that Vulnerable road users (VRUs) are the main victims of road accidents on this road and their share of fatalities are $63.41 \%$ in $2011,52.77 \%$ in 2012 , $44.18 \%$ in 2013 . The main reason behind these accidents are that heavy cross movement of pedestrians and erosion of shoulders due to cattle crossing. As the highway passes through a number of villages and many commercial activities have been observed along the highway. 


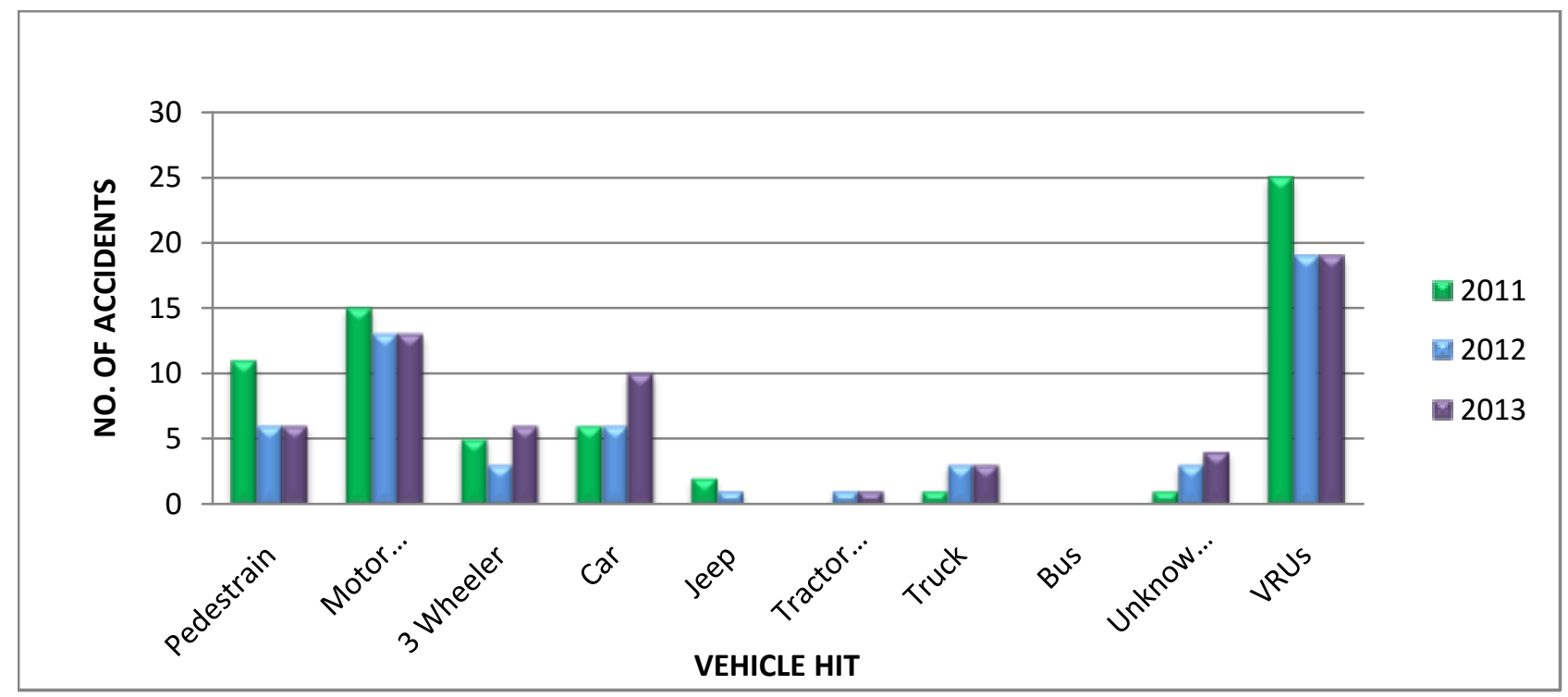

Figure 8: Analysis of accidents as per vehicle hit

\section{Analysis of accident as per Kilometer wise}

To find accident prone stretches or black spots points from 0.00 to $30.60 \mathrm{Km}$, we have collected accident data from the records of FIRs of respective Police head offices and Police stations for the years 2011 - 2013. It can be analyzed that the accidents are occurring from $1^{\text {st }}$ to $8^{\text {th }}$ kilometersand $24^{\text {th }}$ to $26^{\text {th }}$ kilometers. The share of accidents for $1^{\text {st }}$ to $8^{\text {th }}$ kilometers occurs in between $4.65 \%$ to $23.26 \%$ and for $24^{\text {th }}$ to $26^{\text {th }}$ kilometers is $13.89 \%$ to $23.26 \%$.

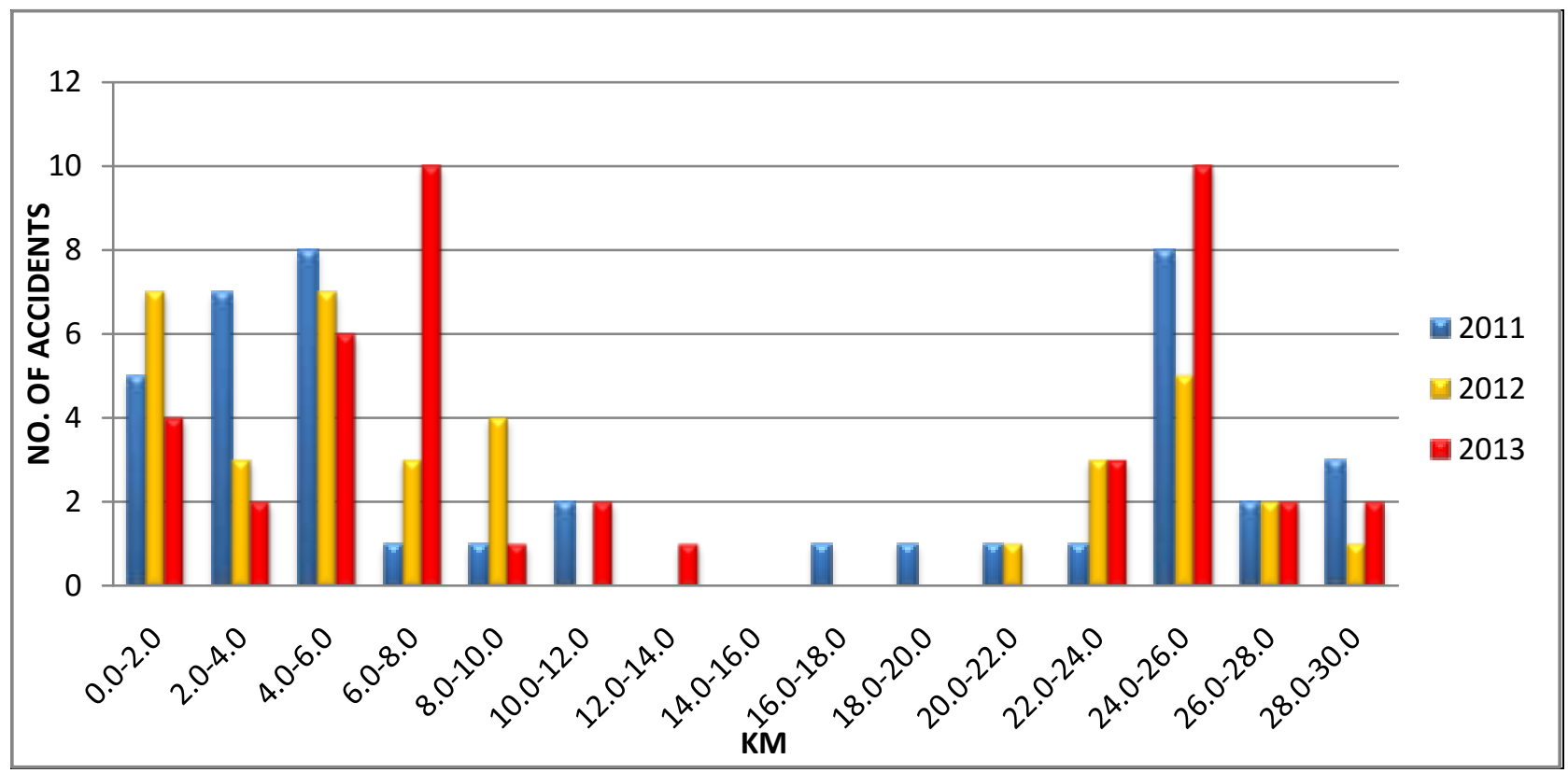

Figure 9: Analysis of accidents as per Kilometer Wise 


\section{Black Spot Locations}
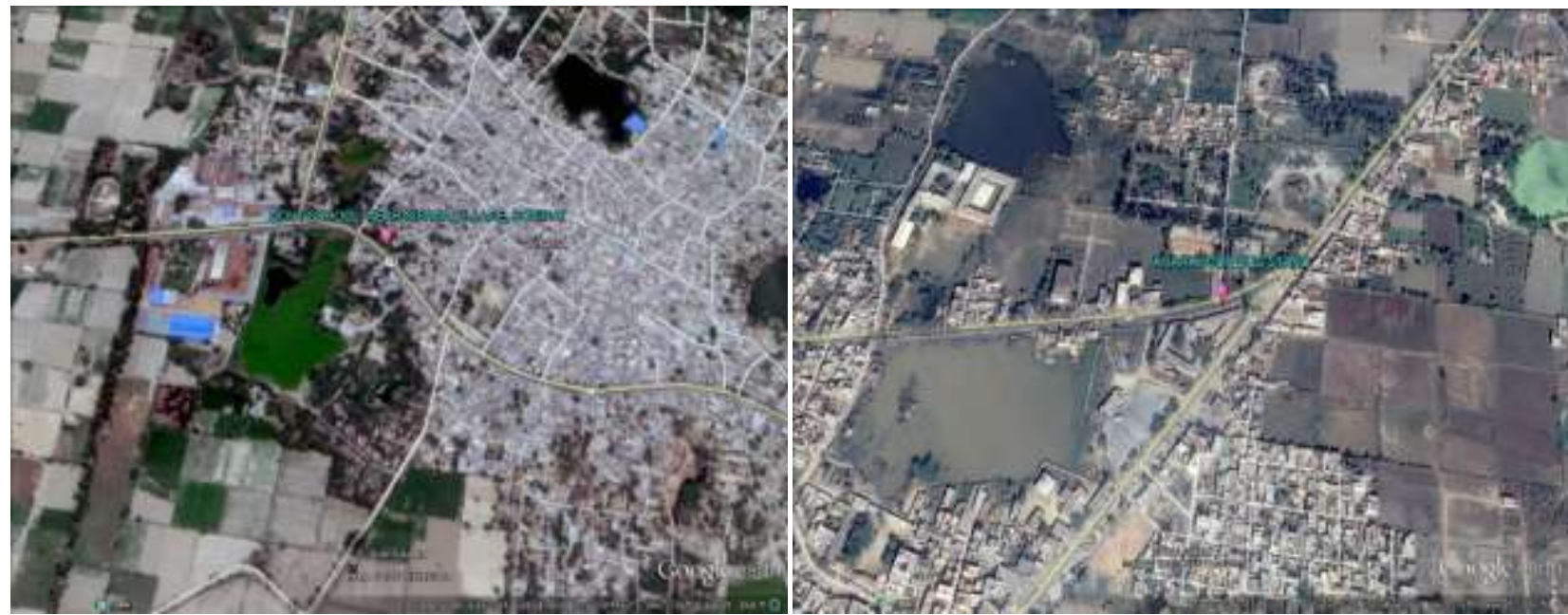

Near Bus stop Sisana village, SonepatInterconnecting road of SH-18 to SH-20, near Kharkhoda bus stop, Sonipat

\section{Observations}

- All the junctions havingno pedestrian crossing sign, road markings. (e.g: Shiela Bypass junctions, Staggered junction of sector $-2,3(\mathrm{P})$, Rohtak).

- Though almost places the lack of proper facilities for physically disabled people have been spotted hence, proper action is needed.

- Unauthorized medianalong theRohtak - Kharkhoda road. (e.g: unauthorized median at Basantvihar, Ramgopal colony, Inderprasth colony, Bohar village, Bhalaut village, Sisana village and nearby all petrol pumps).

- No additional width for "vulnerable road users" e.g. Pedestrians, cyclists, animal drawn vehicles in the whole road stretch i.e there is no separate footpath for pedestrians and no cycle track for bye cyclists.

- Alignment is inconsistent - width suddenly gets restricted to about $6 \mathrm{~m}$ at almost all villages. This is due to land encroached by the villagers along both sides of road.

- Proper marking/highlighting at bus stops missing. (e.g: Shiela bypass bus stop and all villages bus stops on this road).

- Shoulders are not trafficable for road users, including animal drawn vehicles.

- Uselesstraffic signals, fade markings/high lightings or no cat eyes at bus stops during night. (e.g: Shiela bypass bus stop, new bypass near Bohar village, underpass near Silver oaks school and all villages bus stops on this road).

- Trees and vegetation obstruct driver and pedestrian visibility.

- Missing/improper median marking (e.g: at all stops and junctions).

- Normal width not available $(2 \times 3.50 \mathrm{~m} \mathrm{CW}+2 \times 1.5 \mathrm{~m}$ shoulder $=10 \mathrm{~m})$ (as per DPR).

- Nospeed limit signs along the Rohtak-Sonipat road.

- Adequate side slopes not provided $(2: 1)$.

- Need of up gradation ofroad surface at few places on this road. (e.g: nearBohar village, Humayunpur village.)

\section{CONCLUSION}

Based on the present study of road accident characteristics of State Highway - 18 the following conclusions have been drawn:

- Most of the accidents are occurring during day hours. The accidents have occurred during $8 \mathrm{am}$ to $10 \mathrm{am}$ and $4 \mathrm{pm}$ to $6 \mathrm{pm}$.

- Two-wheelers, cars and trucks contribute to majority of accidents.

- Analyzing kilometer wise accidentsoccurring from 0 to 8 $\mathrm{km}$ and 24 to $26 \mathrm{~km}$ are associated with higher accidents. These stretches pass through the urban area or through the villages. Junction of sector - 2,3 (p), Rohtak, new bypass near Bohar village, bus stop near Sisana village and interconnecting road of SH-18 to SH-20 near Kharkhoda bus stand are the most accident prone locations.

- High traffic volume exceeding the capacity, high speeds, absence of road markings, poor condition of shoulders, poor illumination on road, no warning signs and absence of delineators and retro-reflective signs, unauthorized median openings, poor carriageway condition at certain stretches and inadequate provisions for crossing for local traffic including pedestrians and agricultural vehicles were observed as main factors for causing accidents.

\section{RECOMMENDATIONS}

The following measures have been suggested to improve the safety of drivers and vulnerable road users at the study stretches.

I. Provision of warning signs and road markings at unauthorized median openings, at minor village accesses, pedestrian crossings, at sharp curves and other such places along with lighting at black spots is urgently required to bring down high accident rates.

II. As the capacity is exceeded by traffic the road urgently needs widening or up-gradation to four lane divided highway. 
III. Introduce highway patrol to enforce traffic rules and regulations and identify unauthorized encroachments. A check should be made on the illegal auto rickshaw stands mushrooming on the entire road stretch. Also enforcement measures should be taken up to force the auto rickshaws to vacate the illegally occupied spaces on road.

IV. In urban areas with heavy pedestrian movements, pedestrians facilities should be properly designed and pedestrians should be given the right to cross.

\section{REFERENCES}

[1] BagiArun S, Kumar Dheeraj N. Road Safet Audit on SH-87, Karnataka.IOSRJMCE, ISSN : 2278-1684, vol.I, PP. 01-08, 2012.

[2] OzaDaksheshkumar B., Prof. S.M. Damodariya,"RSA for Kapurai-Dabhoi section of SH-11, Global Journal for Research Anlaysis, Vol.3, Issue-7, ISSN : 22778160, 2014.

[3] Rao Srinivas B., Madhu E., Jalihal Santosh, Reddy T.S. Accident study on NH-5 between Anakapalli to Visakhapatnam. Proceedings of the Eastern Asia Society for Transportation Studies, Vol.5, pp. 1973 1983, 2005.

[4] Vashi B.D and Damodariya S.M (2012), A case study of road accidents of Vadodara city in Gujarat state using simulation and ann technique.

[5] Garnaik Mohan Mohita (2014). Effects of highway geometric elements on accident modeling.

[6] Daksheshkumar B. Oza and Damodariya S.M (2014). Road safety audit for Kapural-Dadbhoi section of SH11, Gujarat.

[7] Babkov, V. F. (1975), Road Conditions and Traffic Safety, Mir Publishers, Moscow, 1975.

[8] Manual for Safety in Road Design - A Guide for Indian Highway Engineers, CRRI, TRL, Ross Silcock, June 1998.

[9] RTA. Technical Directions for Road Safety Practitioners. TD 2004/RS01, March 2014.

[10] Traffic \& Transport Planning, annual report 2011-12, CSIR-Central Road Research Institute, Delhi.

[11] Road Accidents in India report -2013. Ministry of Road Transport \& Highways, Transport Research Wing, New Delhi.

[12] WHO. Global Status Report on Road Safety 2013.

[13] Code of Practice for Road Signs, IRC :67-2010.

[14] Manual for Road Traffic \& Work Zone Safety, NHAI 2012.

[15]FHWA. Indian Reservation Safety Improvement Program: A Methodology and Case study, FHWA-WY13/07F, October 2013.

[16] NCRB, SCRB. Reports 2011,2012,2013.

[17] Police Stations. Urban Estate, sec-3, Rohtak and Kharkhoda, Sonipat.

[18] HSRDC DPR Report (Rohtak-Kharkhoda Road) 2007.

[19] TCP Haryana, Report 2014. 